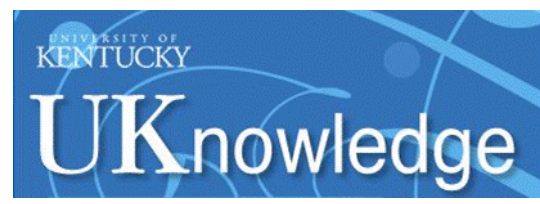

University of Kentucky

UKnowledge

$10-2001$

\title{
Mysterious Rectal Bleeding in a Female Adolescent
}

Hatim A. Omar

University of Kentucky, hatim.omar@uky.edu

Follow this and additional works at: https://uknowledge.uky.edu/pediatrics_facpub

Part of the Pediatrics Commons

Right click to open a feedback form in a new tab to let us know how this document benefits you.

\section{Repository Citation}

Omar, Hatim A., "Mysterious Rectal Bleeding in a Female Adolescent" (2001). Pediatrics Faculty Publications. 87.

https://uknowledge.uky.edu/pediatrics_facpub/87

This Article is brought to you for free and open access by the Pediatrics at UKnowledge. It has been accepted for inclusion in Pediatrics Faculty Publications by an authorized administrator of UKnowledge. For more information, please contact UKnowledge@lsv.uky.edu. 


\section{Mysterious Rectal Bleeding in a Female Adolescent}

Digital Object Identifier (DOI)

http://dx.doi.org/10.1515/IJAMH.2001.13.4.335

\section{Notes/Citation Information}

Published in International Journal of Adolescent Medicine and Health, v. 13, no. 4, p. 335-337.

(c) Freund Publishing House Ltd.

The copyright holder has granted permission for posting the article here. 


\title{
Mysterious rectal bleeding in a female adolescent
}

\author{
Hatim A. Omar, MD
}

Section of Adolescent Medicine, Department of Pediatrics, University of Kentucky, Lexington, Kentucky, United States of America

Abstract: A 15-year-old female referred to our adolescent clinic for further evaluation of rectal bleeding was seen a week earlier in the acute care clinic with a two-day history of bright red rectal bleeding. The physical examination at that time was reportedly normal, including the rectal exam. The blood count with differential, liver function tests, ESR, and barium enema were all within normal limits. The patient, however, continued to complain of rectal bleeding and this led to the referral. She was known in the adolescent clinic as having a history of learning disability and mild mental retardation. She was started on depot medroxy-progesterone acetate one month earlier and had been sexually active since age 13. Additional history with specific questions revealed that the "heavy" bleeding always happened with bowel movements. Physical examination and pelvic ultrasound showed a slightly enlarged uterus and thickened endometrium. Sonohysterogram was done and two posterior polyps were identified. The patıent undenwent endometrial ablation without complications, and no further bleeding was reported on follow-up for three months. Endometrial polyps are rare in adolescents, but should be in the differential diagnosis of vaginal bleeding.

Keywords: Rectal bleeding, cndometrial polyp, adolescent female, United States

Correspondence: Hatim Omar, MD, Associate Professor, Director of Adolescent Medicine \& Young Parent programs, J422, Kentucky Clinic,University of Kentucky, Lexington, KY 40536-0284, United States. Tel: 859-323-6426 ext. 307, Fax. 859-257-7706, E-mail: haomar2@pop.uky.edu

Submitted: February 5, 2001. Revised: February 19, 2001. Accepted: February 20, 2001.

\section{INTRODUCTION}

Rectal bleeding in the adolescent age group is usually a presenting symptom of various gastrointestinal diseases, sexually transmitted diseases involving the rectum, or simple fissure. Work-up of patients is usually directed toward these causes.

A 15-year-old female was referred to our adolescent clinic from the pediatric acute care clinic for further evaluation of rectal bleeding. The patient had presented to the acute care clinic a week earlier with a two-day history of bright red rectal bleeding. This unusual case of rectal bleeding from our program will be presented.

\section{CASE REPORT}

A fifteen-year-old female was referred to the adolescent clinic from the pediatric acute care clinic for further evaluation of rectal bleeding. The patient had presented to the acute care clinic two weeks earlier with a two-day history of bright red rectal bleeding. The physical exam at that time was reportedly normal, including rectal exam. Blood count with differential, liver function tests, erythrocyte sedimentation rate, and barium enema were all within normal limits.

The patient, however, continued to complain of rectal bleeding and this led to the referral. The patient was known in adolescent clinic with prior history of learning disability and mild mental retardation. She was started on depot medroxyprogesterone acetate one month earlier and had been sexually active since age of 13 years. The patient denied use of any medication or illicit drugs. Additional history with specific questions revealed that 


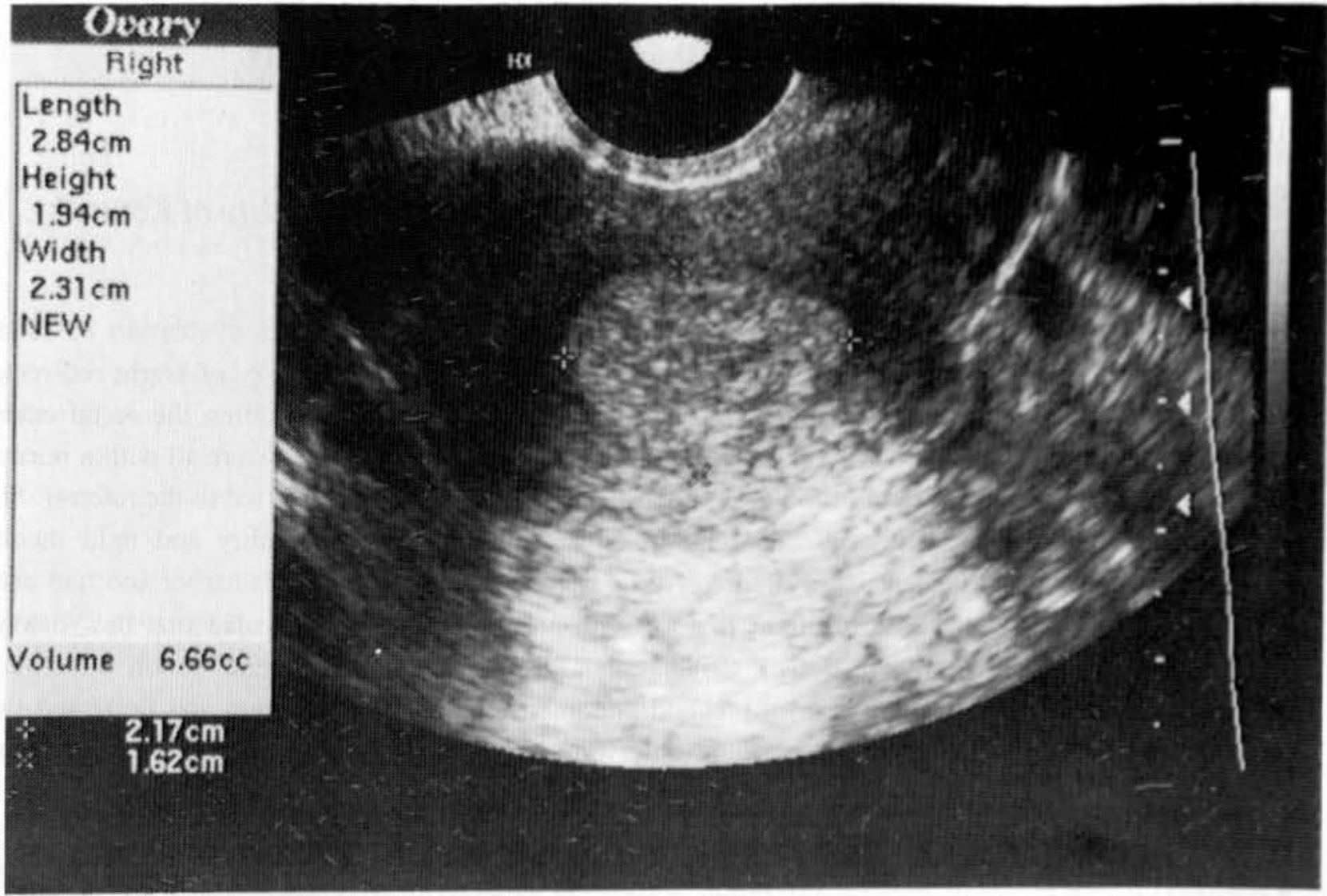

Fig. 1: Ultrasound picture showing thickened endometrium (between the $\mathrm{x}$ marks).

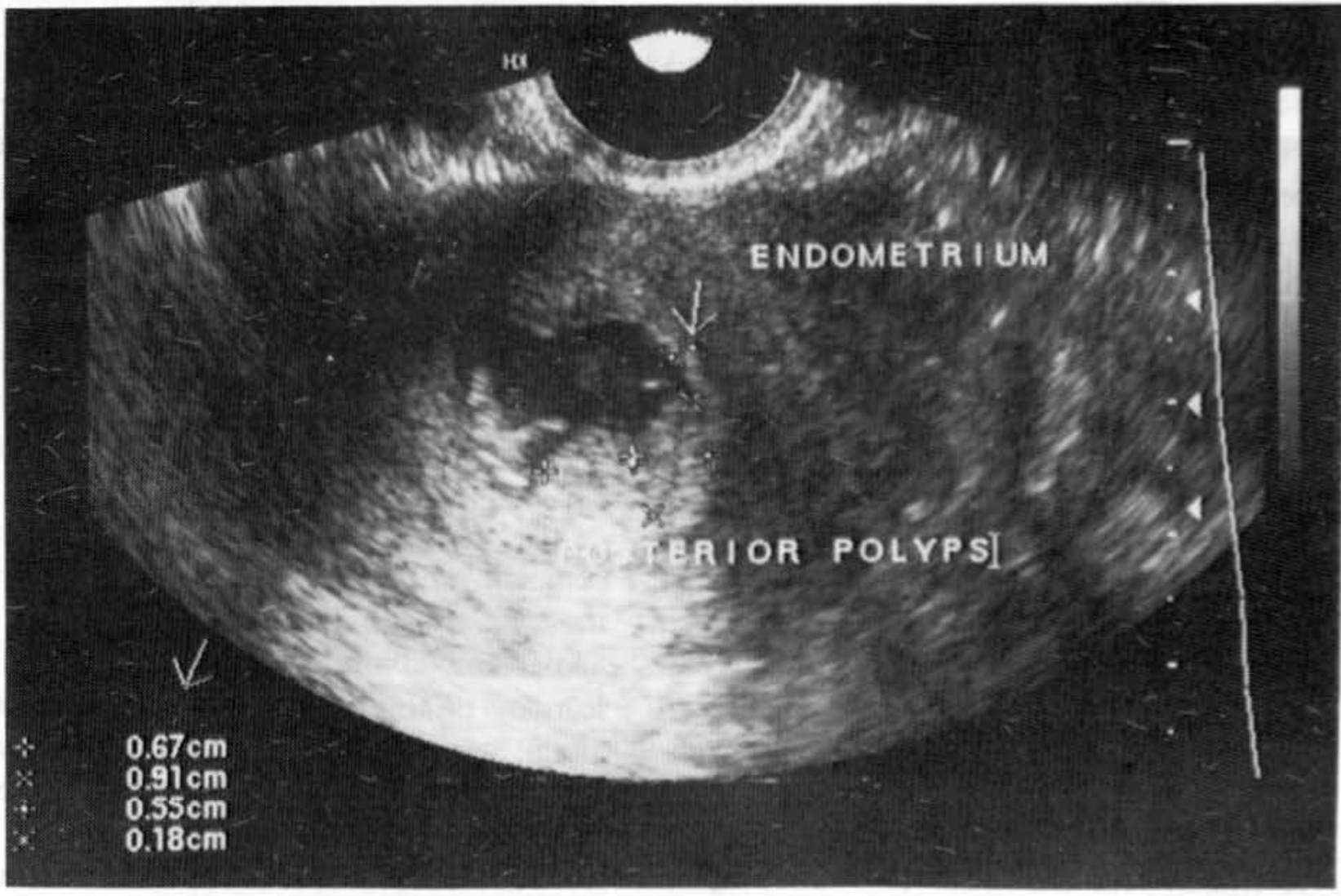

Fig. 2: Sonohysterogram showing two posterior polyps. 
the "heavy" bleeding always happened with bowel movement following straining, because of irregular bowel movements and hard stools.

The patient had normal vital signs, height, weight and body mass index were at the $25 \%$ percentile for age. No notable abnormalities appeared on the physical exam. A rectal exam failed to show blood, but the vagina felt full and the uterus slightly larger than normal. A pelvic exam revealed significant clotted blood in the vagina, mild bleeding from the cervix, and confirmed the enlarged size of the uterus. A pelvic ultrasound showed slightly enlarged uterus and thickened endometrium (Fig. 1). Sonohysterogram was performed and two posterior polyps were identified (Fig. 2). Repeat blood count at this time showed mild anemia (hematocrit of 29). The patient underwent endometrial ablation without complications and no further bleeding was reported on follow-up for three months.

\section{DISCUSSION}

Rectal bleeding in the adolescent age group is usually the result of gastrointestinal diseases, acute infections including sexually transmitted diseases of the rectum, simple fissures, or chronic constipation. The first step in evaluating such symptoms is a thorough history to confirm the rectal nature of the bleeding and its characteristics. It is not always easy for the patient to be sure that the bleeding is rectal, since it is usually noticed as bloodstain on the underwear or in the toilet bowl.

Patients with learning disability and mild intellectual disability, as was the case in this patient, are even less likely to differentiate between rectal and vaginal bleeding, especially when the blood is noticed only after bowel movement.

In the case described above, the bleeding occurred after increase in intraabdominal pressure during defecation. This is consistent with bleeding in the vagina that leaks out following straining. Abnormal vaginal bleeding is common in adolescents (1) and can originate from the uterus, vagina, cervix, or a variety of systemic causes (1-3). In this case the bleeding was caused by endometrial polyps, which are usually rare in adolescents with no known rate of occurrence. The concern about gastrointestinal causes for the bleeding in this patient led to a two-week delay in diagnosis and treatment, causing the development of anemia in addition to the expensive work-up of rectal bleeding. All the above could have been avoided with a thorough, age-appropriate history and a pelvic exam.

\section{CONCLUSION}

A thorough history continues to be extremely important when evaluating adolescents. Straightforward, direct, and well-selected questions should be used, especially when dealing with developmentally-delayed patients. Genital bleeding should not be attributed to injectable contraceptives without thorough evaluation. Endometrial polyps are rare in adolescents, but should be in the differential diagnosis of vaginal bleeding.

\section{ACKNOWLEDGEMENTS}

This study was presented in part at the $13^{\text {th }}$ Annual Meeting of the North American Society of Pediatric and Adolescent Gynecology, New Orleans, LA, May 1999.

\section{REFERENCES}

1. Emans JS, Bravender T. Menstrual disorders: dysfunctional uterine bleeding. Pediatr Clin North Am 1999;46:545-53.

2. Bacon J. Dysfunctional uterine bleeding: diagnosis and treatment in adolescents. Supplement to The Female Patient 2000:21-7.

3. Hillard PJ. Diagnosing and controlling abnormal uterine bleeding. Contemp Adolesc 1999;4:4. 


\section{BITS 'N PIECES}

\section{Unlicensed and off label prescribing of drugs in general practice}

AIM: To determine the incidence and nature of unlicensed and off label prescribing of drugs for children in general practice.

METHODS: A retrospective analysis of all prescriptions for one year involving children (aged 12 years or under) from a single suburban general practice in the English Midlands. Prescribed drugs were categorised as licensed, unlicensed (without a product licence), or used in an off label way (outside the terms of their product licence).

RESULTS: During 1997 there were 3347 prescription items involving 1175 children and 160 different drugs. A total of $2828(84.5 \%)$ prescriptions were for licensed medicines used in a licensed way; $10(0.3 \%)$ were for unlicensed medicines; and $351(10.5 \%)$ were licensed medicines used in an off label way. For $158(4.7 \%)$ the information was insufficient to determine licence status.

CONCLUSION: This is the first study to show that a significant number of drugs prescribed for children by general practitioners are off label and highlights the anomalies and inadequacies of drug information for prescribers.

McIntyrea J, Conroya S, Averyb A, Cornsa H, Choonaraa I. Arch Dis Child 2000;83:498-501. 